DOI: https://doi.org/10.33330/jurteksi.v7i1.921

Available online at http://jurnal.stmikroyal.ac.id/index.php/jurteksi

\title{
PENERAPAN FUZZY INFERENCE SYSTEM PEMILIHAN DESAIN INTERIOR
}

\author{
Nanda Jarti ${ }^{1}$, Weni Lestari Putri ${ }^{1}$ \\ ${ }^{1}$ Teknik Informatika, Fakultas Teknik, Universitas Ibnu Sina \\ Email : *nandaluthan@gmail.com
}

\begin{abstract}
Interior design is currently growing. This can be seen from the various designs in each building. Each design has different characteristics and shapes. The problem that is often experienced by users is the lack of user knowledge in the field of interior design so that after the design is finished, the user is not satisfied with the results of the interior design. The main objective of this research is a decision making system in selecting interior designs according to user needs by paying attention to criteria such as design form, design size, material and quality. The method of selecting interior design using the Mamdani method. The mamdani method is very suitable in calculating the output value of each criterion value and the end result becomes the reference value in making a decision. The resulting system is in the form of design selection criteria according to user needs. Thus the results of this study get an Output value of 427,368 which is in the range with the value considered.
\end{abstract}

Keywords: fuzzy inference system; interior design; mamdani method; software matlab.

\begin{abstract}
Abstrak: Desain Interior saat ini semakin berkembang, Hal ini bisa dilihat dari berbagai desain pada setiap bangunan. Setiap desain memiliki karakteristik dan bentuk yang berbeda beda. Permasalahan yang sering dialami pengguna yaitu kurangnya pengetahuan pengguna dibidang desain interior sehingga setelah desain selesai dikerjakan pengguna tidak Puas dengan hasil desain interior. Tujuan utama penelitian ini berupa Sistem pengambilan keputusan dalam pemilihan desain interior sesuai dengan kebutuhan pengguna dengan memperhatikan kriteria seperti Bentuk Desain, ukuran desain, bahan dan Kualitas. Metode pemilihan Desain interior menggunakan metode Mamdani. Metode mamdani sangat cocok dalam menghitung nilai output dari masing masing nilai kriteria dan hasil akhirnya menjadi nilai acuan dalam pengambilan sebuah Keputusan. Sistem yang dihasilkan berupa kriteria pemilihan desain sesuai kebutuhan pengguna. Dengan demikian Hasil penelitian ini mendapatkan nilai Output sebesar 427.368 yang berada pada range dengan nilai dipertimbangkan.
\end{abstract}

Kata kunci: desain interior; fuzzy inference system; metode mamdani; software matlab. 


\section{PENDAHULUAN}

Logika fuzzy bagian dari sebuah metodologi sistem pemecahan masalah yang bisa di implementasikan kedalam sebuah sistem. Bagian penyelesaian logika fuzzy mulai dari permasalahan kecil, menengah dan luas, sehingga bisa dijadikan sebagai sistem pemecahan masalah dalam mengambil sebuah sistem keputusan [1],[2]. Logika Fuzzy bisa digunakan diberbagai cabang ilmu seperti pada sebuah sistem diagnonosis penyakit (dalam ilmu kedokteran), dibidang pemasaran, bidang ekonomVi(riset operasi), kendali kualitas air, pencocokan pola (dalam bidang teknik),Vprediksi gempa bumi dan yang lain-lain[3]. Secara garis besar logika fuzzy mampu menyelesaikan sebuah perhitungan matematika dengan proses menghitung dan memutuskan sebuah nilai dengan benar[4]. Bisa dijadikan sebuah Sistem pendukung keputusan dalam menentukan indikator indikator permasalah[5].Sebuah komputasi cerdas yang mampu mengukur range subuah nilai[6]. dan memprediksi suatu sistem[7]. Saat sekarang ini logika fuzzy sudah banyak digunakan orang dalam suatu penelitian, ada beberapa alasan mengapa orang menggunakan logika fuzzy diantaranya: [8] 1. Kosep yang digunakan mudah dipahami. 2. Fuzzy Lebih Fleksibel. 3. Memiliki tolerasi pada data. 4. Berdasarkan pengalaman para pakar tanpa harus melakukan kegiatan pelatihan. 5. Menggunakan Bahasa forma sehingga mudah dipahami oleh orang awam.

Permasalahan yang sering terjadi di kalangan pengguna seperti kurangnya pengetahuan user dalam pemilihan desain interior, sehingga setelah bangunan selesai dan dilengkapi dengan desain interior namun banyak user yang tidak puas dengan hasil desain yang telah selesai.
Saat ini Artificial intelegence sudah bisa digunakan untuk berbagai macam bentuk penelitian. Pendekatan berbasis logika fuzzy memberikan solusi dalam pengambilan sebuah keputusan. Cara kerja logika fuzzy mampu menentukan kumpulan Rule Rule dalam bentuk IF THEN, mengubah nilai input menjadi nilai tegas di konversikan dalam bentuk nilai lingguistik dan disimpan dalam basis pengetahuan, Proses mengubah nilai input fuzzy berdasarkan rule yang telah ditetapkan pada basis pengetahuan dan proses pengubahan nilai output berdasarkan mesin inferensi menjadi nilai tegas dengan menggunakan nilai keanggotaan.[9] Hasil penelitian yang dilakukan oleh [10]. Fuzzy logic merupakan sebuah sistem cerdas sistem pakar atau bisa juga dikenal dengan Sistem pengambilan keputusan, Keunikan dari motode yang digunakan berupa penilaian menggunakan derjat keanggotaan tersebut memiliki sebuah nilai tentang suatu variabel berdasarkan hitungan lingguistiknya, tujuaan utama penelitian ini berupa naik turunnya data penjualan[11]. Penelitian Oleh [12] Hasil akhir penelitian dari sebuah percobaan dengan menggunakan perangkat Matlab dan toolbox logica fuzzy menghasilkan nilai yang lebih baik dan tidak lebih mudah dengan cara perhitungan manual.

[13] Perancangan dan Implementasi Fuzzy Inference System (FIS) Metode Tsukamoto pada Penentuan Penghuni Asrama pada tahun diteliti pada tahun (2018), dengan pemaparan kelebihan logika fuzzy dapat di istilahkan dengan logika kabur dengan memperoleh nilai, membangun, serta diaplikasikan melakui pengalaman para ahli langsung sehingga tidak perlu melakukan proses pelatihan secara langsung. [14] Kasus yang berhubungan dengan Fuzzy inference system dapat dipecahkan menggunakan tiga 
metode yaitu metode Mamdani, Sugeno dan Tsukamoto [15]. Bentuk dari suatu komputasi yang digunakan pada teori Fuzzy infernce system adalah aturan dan himpunan fuzzy. Bagian besar input nilai crisp dimasukkan kedalam FIS, Kemudian dilanjutkan kedalam basis pengetahuan dan rule dalam bentuk IF THEN. Jika jumlah aturan lebih dari satu maka dilakukan inferensi dari keseluruhan aturan. Untuk melakukan nilai tegas atau nilai akhir dibutuhkan defuzifikasi[16].

Tujuan penelitian ini adalah membuat desain interior sesuai dengan kebutuhan pengguna, Khususnya pembuatan desain interior dikota Batam dengan menggunakan Fuzzy Logic metode Mamdani. Penelitian Ini memberika Solusi berupa Sistem Pengambilan Keputusan dalam Pemelihan Desain Interior Sesuai dengan Kebutuhan Pengguna. Setelah Desain Interior sudah selesai dibangun pengguna kenyamanan saat dilihat, dan Merasa nyaman saat berada dirungan tersebut.

\section{METODE}

Metode Mamdani adalah sebuah metode yang menggunakan nilai maxmin serta menggunakan operator or Untuk mendapatkan output nya diperlukan tahapan metode mamdani sebagai berikut:

a. Pembentukan himpunan fuzzy. Pada metode Fuzzy Mamdani, baik variabel input maupun variabel output dibagi menjadi satu atau lebih himpunan fuzzy.

b. Aplikasi fungsi Implikasi. Pada Fuzzy Mamdani, fungsi implikasi yang digunakan adalah Min.

c. Komposisi Aturan. Tidak seperti penalaran monoton, apabila sistem terdiri dari beberapa aturan, maka in- ferensi diperoleh dari kumpulan dan korelasi antar aturan.

d. Penegasan (defuzzifikasi). Defuzifikasi adalah cara

$$
Z^{*}=\frac{\int_{Z} 2 \mu(z) d z}{\int_{Z} \mu(z) d z}
$$

untuk memperoleh nilai tegas (crisp) dari himpunan fuzzy. Metode defuzzifikasi yang digunakan pada metode Mamdani, yaitu metode centroid (composite moments). Pada metode ini, penegasan diperoleh dengan cara mengambil titik pusat ( $\left.\mathrm{z}^{*}\right)$ daerah fuzzy[19].

Analisa Sistem yang diperoleh terdapat 4 variabel input yaitu: Bentuk,Ukuran, Harga dan kualitas Bahan. Untuk menyelesaikan kasus penelitian ini menggunakan Software Aplikasi MATLAB. Aplikasi ini bisa menghasilkan nilai Output dalam memilihan desain interior.

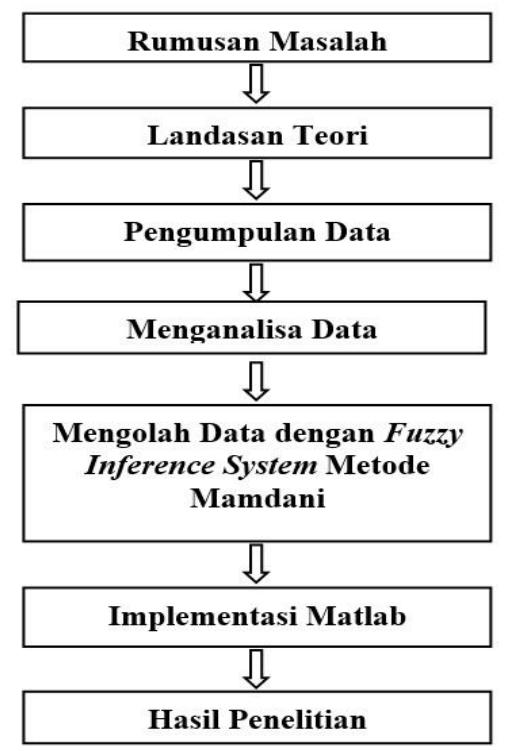

Gambar 1. Metode Penelitian

\section{HASIL DAN PEMBAHASAN}

Tahap awal pembahasan pada an- 
alisa fuzzy berupa pengolahan data, Data ini dikelompokkan berdasarkan indicator yang diperoleh,setelaah itu di uraikan sesuai urutan cara kerja dari fuzzy itu sendiri.

Hasil pengumpulan data dalam penelitian desain interior dikelompokkan berdasarkan fungsi indicator penilaian. Dibawah ini merupakan table indicator dan semesta pembicaraan sesuai dengan Range yang telah ditentukan. Range data merupakan aturan nilai terendah dan tertinggi dari sebuah pengolahan data Tersebut.

Proses fungsi masing masing variabel pemilihan desain interior. Berdasarkan fungsi derjat keanggotaannya.

Pada Kasus ini terdapat 4 Variabel input dan 1 varibel output, Variabel input yaitu Bentuk, Ukuran, Harga dan Kualitas Bahan sedangkan Variabel Ouput yaitu berupa Keputusan. Dibawah ini akan dijelaskan proses masing masing variable. Diantaranya:

a. Variabel Membership Fungsion Bentuk

Dalam pemilihan Desain Interior Bentuk yang akan dipilih harus dipertimbangkan sesuai kebutuhan peng-guna. Pemilihan Bentuk dibagi menjadi 3 bagian diantaranya, Cukup Menarik, Menarik, Sangat menarik. b. Variabel Membership Fungsion Harga

Penentuah harga dapat dikelompokkan kedalam 2 bagian, yaitu faktor internal dan faktor eksternal. Logika fuzzy dapat dijadikan sebuah acuan dalam menyelesaikan masalah ini, karena lagika fuzzy mampu menentukan parameter parameter harga. Dalam Setiap Pembelian pengguna selalu mempertimbangkan Harga. Samakin tinggi harga desain interior makan akan semakin bagus hasil yang didapatkan, begitu juga sebaliknya, Harga dibagi Menjadi 3 Bagian, Murah, sedang, Mahal.

c. Variabel Membership Fungsion Kualitas Bahan

Bahan dalam pembuatan Desain Interior sangat bervariasi, Mulai dari bahan sederhana hingga bahan yang berkualitas Tinggi. Hal tersebut bisa dijadikan acuan bagi pengguna.

d. Variabel Membership Fungsion Keputusan

Dari pembahasan masing masing Variabel, User bisa mengambil keputusan dalam mempertimbangkan Desain Interior yang akan dipilih.

Proses selanjutnya menentukan pembagian himpunan fuzzy dan masing masing domain untuk mendapatkan hasil pencarian nilai $\mathrm{Z}$.

Tabel 1. Himpunan Kabur

\begin{tabular}{lll}
\hline Fungsi & Nama Variabel & Semesta Pembicaraan \\
\hline \multirow{2}{*}{ Input } & Bentuk & {$\left[\begin{array}{ll}0 & 100\end{array}\right]$} \\
\cline { 2 - 3 } & Ukuran & {$\left[\begin{array}{ll}0 & 10\end{array}\right]$} \\
\cline { 2 - 3 } & Harga & {$\left[\begin{array}{ll}0 & 1000\end{array}\right]$} \\
\cline { 2 - 3 } & Kualitas Bahan & {$\left[\begin{array}{ll}0 & 80\end{array}\right]$} \\
\hline Output & Keputusan & {$\left[\begin{array}{ll}0 & 100\end{array}\right]$} \\
\hline
\end{tabular}


Tabel 2. Domain Himpunan Fuzzy

\begin{tabular}{|c|c|c|}
\hline Variabel & Nama Himpunan Fuzzy & Domain \\
\hline \multirow{3}{*}{ Bentuk } & Sangat Menarik & {$\left[\begin{array}{lllll}70 & 85 & 100 & 100\end{array}\right]$} \\
\hline & Menarik & {$\left[\begin{array}{llll}50 & 70 & 85\end{array}\right]$} \\
\hline & Cukup Menarik & {$\left[\begin{array}{llll}0 & 0 & 50 & 65\end{array}\right]$} \\
\hline \multirow{3}{*}{ Ukuran } & Luas & {$\left[\begin{array}{llll}6 & 8 & 10 & 10\end{array}\right]$} \\
\hline & Sedang & {$\left[\begin{array}{lll}4 & 6 & 8\end{array}\right]$} \\
\hline & Kecil & {$\left[\begin{array}{llll}0 & 0 & 4 & 6\end{array}\right]$} \\
\hline \multirow{3}{*}{ Harga } & Mahal & {$\left[\begin{array}{llllll}600 & 800 & 1000 & 1000\end{array}\right]$} \\
\hline & Sedang & [400 6000800$]$ \\
\hline & Murah & {$\left[\begin{array}{lllll}0 & 0 & 400 & 600\end{array}\right]$} \\
\hline \multirow[t]{3}{*}{ Kualitas Bahan } & Sangat Bagus & {$\left[\begin{array}{lllll}45 & 65 & 80 & 80\end{array}\right]$} \\
\hline & Bagus & {$\left[\begin{array}{lll}30 & 45 & 60\end{array}\right]$} \\
\hline & Cukup Bagus & {$\left[\begin{array}{llll}0 & 0 & 30 & 45\end{array}\right]$} \\
\hline \multirow[t]{3}{*}{ Keputusan } & Dibeli & {$\left[\begin{array}{lllll}70 & 80 & 100 & 100\end{array}\right]$} \\
\hline & Pertimbangkan & {$\left[\begin{array}{llll}60 & 70 & 80\end{array}\right]$} \\
\hline & Tidak Beli & 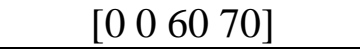 \\
\hline
\end{tabular}

Tabel 3. Domain Himpunan Fuzzy Bentuk

\begin{tabular}{llll}
\hline Nama Variabel & Himpunan & Semesta Pembicaraan & Domain \\
\hline Bentuk & Cukup Menarik & {$\left[\begin{array}{llll}0 & 0 & 50 & 65\end{array}\right]$} & {$\left[\begin{array}{ll}0 & 65\end{array}\right]$} \\
& Menarik & {$\left[\begin{array}{llll}50 & 70 & 85\end{array}\right]$} & {$\left[\begin{array}{lll}50 & 85\end{array}\right]$} \\
& Sangat Menarik & {$\left[\begin{array}{llll}70 & 85 & 100 & 100\end{array}\right]$} & {$\left[\begin{array}{lll}70 & 100\end{array}\right]$} \\
\hline
\end{tabular}

Tabel 4. Domain Himpunan Fuzzy Ukuran

\begin{tabular}{llll}
\hline Nama Variabel & Himpunan & $\begin{array}{l}\text { Semesta Pembic- } \\
\text { araan }\end{array}$ & Domain \\
\hline Harga & Kecil & {$\left[\begin{array}{llll}0 & 0 & 4 & 6\end{array}\right]$} & {$\left[\begin{array}{ll}0 & 6\end{array}\right]$} \\
\hline & Sedang & {$\left[\begin{array}{lll}4 & 6 & 8\end{array}\right]$} & {$\left[\begin{array}{lll}4 & 8\end{array}\right]$} \\
\hline & Luas & {$\left[\begin{array}{llll}6 & 8 & 10 & 10\end{array}\right]$} & {$\left[\begin{array}{ll}6 & 10\end{array}\right]$} \\
\hline
\end{tabular}

Tabel 5. Domain Himpunan Fuzzy Harga

\begin{tabular}{|c|c|c|c|}
\hline Nama Variabel & Himpunan & Semesta Pembicaraan & Domain \\
\hline \multirow[t]{3}{*}{ Harga } & Murah & 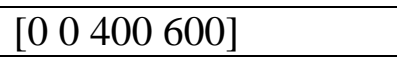 & [0 600] \\
\hline & Sedang & {$\left[\begin{array}{llll}400 & 600 & 800\end{array}\right]$} & [400 800] \\
\hline & Mahal & [ [ [ 6008001000$]$ & [600 1000] \\
\hline
\end{tabular}

Tabel 6. Domain Himpunan Fuzzy Kualitas Bahan

\begin{tabular}{llll}
\hline Nama Variabel & Himpunan & $\begin{array}{l}\text { Semesta Pembic- } \\
\text { araan }\end{array}$ & Domain \\
\hline Kualitas Bahan & Cukup Bagus & {$\left[\begin{array}{llll}0 & 0 & 30 & 45\end{array}\right]$} & {$\left[\begin{array}{ll}0 & 600\end{array}\right]$} \\
\hline & Bagus & {$\left[\begin{array}{llll}30 & 45 & 60\end{array}\right]$} & {$\left[\begin{array}{lll}400 & 800\end{array}\right]$} \\
\hline & Sangat Bagus & {$\left[\begin{array}{llll}45 & 65 & 80 & 80\end{array}\right]$} & {$\left[\begin{array}{lll}6000 & 1000\end{array}\right]$} \\
\hline
\end{tabular}


Dengan demikian, fungsi keanggotaan untuk hasil komposisi.Kemudian kita hitung luas setiap daerah:

$$
\begin{aligned}
\text { A1 } & =0,83 * 600 \\
& =498 \\
\text { A2 } & =(0,83+0,93) * 0,5 \\
& =(1.76 * 0,5) \\
& =1.295 \\
\text { A3 } \quad & =(1000-700) * 0,93 \\
& =300 * 0,93 \\
& =270
\end{aligned}
$$

Titik pusat dapat diperoleh dari:

$$
\begin{aligned}
\mathrm{Z} & =\frac{489+1.295+270}{0,5+0,6+0,7}=\frac{769.295}{1.8} \\
& =427.386
\end{aligned}
$$

Setelah melakukan pencarian nilai $\mathrm{Z}$ dengan manual, langkah selanjutnya adalah memasukkan nilai $\mathrm{Z}$ kedalam Aplikasi Matlab dengan nilai X Bentuk 75, Ukuran 6, Harga 460, dan kualitas 50

Hasil Akhir dari penelitian ini dapat disimpulkan bahwa Pemilihan Desain Interior berada pada nilai 427.368 dengan Keputusan Dipertimbangkann

\section{SIMPULAN}

Pemilihan desain interior menggunakan metode mamdani dan di implementasikan dalam Software matlab bisa dilakukan untuk memperoleh nilai output. Metode mamdani bisa nenentukan nilai bobot berdasarkan kriteria yang digunakan dalam proses perhitungan masing masing variabel. Berdasarkan implementasi pengujian yang dilakukan diperoleh nilai yang sama antara perhitunga manual dan perhitungan sistem. Sehingga bisa dijadikan sebagai sistem pengambilan keputusan dalam pemilihan desain interior.

\section{UCAPAN TERIMA KASIH}

Terima kasih kepada Direktorat Jenderal Penguatan Riset danPengembangan Kemenristek DIKTI, atas pendanaan Penelitian Dosen Pemula (PDP) Tahun Anggaran 2020.

\section{DAFTAR PUSTAKA}

[1] Rizki, S. N. (2018). Fuzzy logic memprediksi tingkat kecelakaan kerja pada PT.Galang Kapal di kota Batam. Digital Zone: Jurnal Teknologi Informasi Dan Котиnikasi, 9(2), 151-161. https://doi.org/10.31849/digitalzon e.v9i2.1980.

[2] Setiani Asih, M. (2018). Sistem Pendukung Keputusan Fuzzy Mamdani pada Alat Penyiraman Tanaman Otomatis. Jurnal Sistem Informasi, 5341(April), 1.

[3] Irawan, M. D., \& Herviana, H. (2019). Implementasi Logika Fuzzy Dalam Menentukan Jurusan Bagi Siswa Baru Sekolah Menengah Kejuruan (Smk) Negeri 1 Air Putih. Jurnal Teknologi Informasi, 2(2), 129. https://doi.org/10.36294/jurti.v2i2 .427

[4] Adrial, R. (2018). Fuzzy Logic Modeling Metode Sugeno Pada Penentuan Tipe Diabetes Melitus Menggunakan MATLAB. Jurnal Ilmiah Informatika, 6(01), 62. https://doi.org/10.33884/jif.v6i01. 423

[5] Rizki, S. N., \& Tipa2, H. (2019). Implementasi Fuzzy Inference System Untuk Mengoptimalkan 
DOI: https://doi.org/10.33330/jurteksi.v7i1.921

Available online at http://jurnal.stmikroyal.ac.id/index.php/jurteksi

Pembagian Beban Koneksi. Digital Zone: Jurnal Teknologi Informasi Dan Komunikasi, $x(1), 1-$ 7.

[6] Larasati, I., Setiawan, B. D., \& Data, M. (2018). Pemilihan Aturan Fuzzy Inference System Mamdani Menggunakan Algoritme Particle Swarm Optimization Dalam Sistem Penyiraman Otomatis Pada Tanaman Tomat. Jurnal Pengembangan Teknologi Informasi Dan Ilmu Komputer (JPTIIK) Universitas Brawijaya, 2(11), 5525-5534.

[7] Pambudi, R. A., Setiawan, B. D., \& Wijoyo, S. H. (2018). Implementasi Fuzzy Time Series untuk Memprediksi Jumlah Kemunculan Titik Api. Jurnal Pengembangan Teknologi Informasi Dan Ilmu Komputer (J-PTIIK) Universitas Brawijaya, 2(11), 47674776.

[8] Wahyudi, I., Bahri, S., \& Handayani, P. (2019). Aplikasi Pembelajaran Pengenalan Budaya Indonesia. V(1), 135-138. https://doi.org/10.31294/jtk.v4i2

[9] Putri, A., \& Effendi. (2017). Fuzzy Logic Untuk Menentukan Lokasi Kios Terbaik Di Kepri Mall Dengan Menggunakan Metode Sugeno. Teknik Informatika, 3, 49-59.

[10] Sitohang, S., \& Denson Napitupulu, R. (2017). Fuzzy Logic Untuk Menentukan Penjualan $\mathrm{Ru}-$ mah Dengan Metode Mamdani (Studi Kasus: Pt Gracia Herald). Jurnal ISD, 2(2), 2528-5114.

[11] Efendi, D. M., \& Ardhy, F. A. (2018). Perbandingan Metode Fuzzy Inferensi Stukamoto Dan Sugeno Untuk Memprediksi
Pemesanan Roti Jordan. Jurnal Tekno Kompak, 12(2), 45. https://doi.org/10.33365/jtk.v12i2 .147

[12] Charolina, Y. (2016). SISTEM PENDUKUNG KEPUTUSAN UNTUK MENENTUKAN PEMBERIAN BONUS TAHUNAN MENGGUNAKAN METODE FUZZY LOGIC TIPE MAMDANI ( Studi Kasus Pada Karyawan PT . Sunhope Indonesia Di Jakarta ). Jurnal Teknologi Informasi, 12, 42-53.

[13] Syahidi, A. A., Biabdillah, F., \& Bachtiar, F. A. (2019). PERANCANGAN DAN IMPLEMENTASI FUZZY INFERENCE SYSTEM (FIS) METODE TSUKAMOTO PADA PENENTUAN PENGHUNI ASRAMA. Jurnal Teknologi Informasi Dan Ilmu Komputer (JTIIK), Vol. 6, No.

[14] Hidayah, E. N., Utami, Y. R. W., \& Laksito Y.S, W. (n.d.). ANALISIS ALGORITMA FUZZY INFERENCE SYSTEM (FIS) MAMDANI PADA SISTEM PENDUKUNG KEPUTUSAN PENJURUSAN SISWA DI SMA NEGERI 1 JATISRONO. Jurnal TIKomSiN.

[15] Alamsyah, \& Muna, I. H. (2016). Metode Fuzzy Inference System untuk Penilaian Kinerja Pegawai Perpustakaan dan Pustakawan. Scientific Journal of Informatics, Vol. 3, No.

[16] Pratama, E. A., \& Fitriani, S. (2017). PENERAPAN METODE FUZZY INFERENCE SYSTEM (FIS) MAMDANI DALAM PENENTUAN PEMBERIAN REWARD KARYAWAN BA- 
DOI: https://doi.org/10.33330/jurteksi.v7i1.921

Available online at http://jurnal.stmikroyal.ac.id/index.php/jurteksi

GIAN PRODUKSI PADA IKM DOCTOR SPEED. Prosiding SINTAK.

[17] Akhirina, T. Y., \& Sonny, M. (2017). Fuzzy Inference System (FIS) dengan Metode Tsukamoto dan Mamdani dalam Menentukan Kelayakan Kenaikan Gaji Karyawan. JURNAL KOMTIKA, Vol. $1 \mathrm{No}$.

[18] Vinsensia, D., \& Utami, Y. (2018). Penerapan Fuzzy Inference System (FIS) Metode Mamdani dalam Pemilihan Jurusan Perguruan Tinggi. Publikasi Jurnal \& Penelitian Teknik Informatika, Volume $2 \mathrm{~N}$.

[19] Puspitasari, A. (2017). PENGGUNAAN FUZZY INFERENCE SYSTEM (FIS) METODE MAMDANI UNTUK MENENTUKAN KINERJA PELAYANAN PDAM. Vol. III,.

[20] Harefa, K. (2017). PENERAPAN
FUZZY INFERENCE SYSTEM

UNTUK MENENTUKAN

JUMLAH PEMBELIAN

PRODUK BERDASARKAN

DATA PERSEDIAAN DAN PENJUALAN. JURNAL INFORMATIKA UNIVERSITAS PAMULANG, Vol. 2, No.

[21] Rahmat. (2019). Analisa Sistem Inference Fuzzy Sugeno Dalam Menentukan Harga Pembelian Tanah Untuk Pembangunan Komplek Perumahan Diwilayah Kutacane Aceh Tenggara. 6(1), 11-17.

[22] Shakiba, A., Hooshmandasl, M. R., Davvaz, B., \& Shahzadeh Fazeli, S. A. (2017). Sapproximation spaces: A fuzzy approach. Iranian Journal of Fuzzy Systems, 14(2), 127-154. https://doi.org/10.22111/ijfs.2017 .3137 . 